\title{
Physico-chemical Characteristics of Sokoto Locally grown Cucumis melo L (Honeydew Melon) Seed Oil
}

\author{
Ishaka Aminu' ${ }^{1 *}$, Aliyu Abubakar Gambo², and Muhammad Hassan Yankuzo' \\ 'Department of Medical Biochemistry, College of Health Sciences, Usmanu Danfodiyo University Sokoto, Nigeria \\ 'Department of Biochemistry, Usmanu Danfodiyo University Sokoto, Nigeria
}

Corresponding Author:

Ishaka Aminu

Department of Medical Biochemistry, College of

Health Sciences, Usmanu Danfodiyo University

Sokoto, Nigeria

E-mail: ameenimaiturare@yahoo.com,

Tel: +2348034011227

\section{Astract}

Introduction: Owing to increase demand for safer and health promoting vegetable oils, a number of potential sources are being explored by researchers.

Materials and Methods: In this study, oil was extracted using Soxhlet from Sokoto locally grown Cucumis melo L (honeydew melon). Physical and chemical properties (colour, moisture, $\mathrm{pH}$, specific gravity, refractive index, acid value, iodine value, saponification value and peroxide value) of the oil were determined using standard analytical methods by Association of Official Analytical Chemists (AOAC).

Results: The results showed the percentage yield of the oil to be $27.46 \%$. Physically, the oil was yellowish in colour, liquid at room temperature, with $\mathrm{pH}$ of $6.2(0.01)$, specific gravity of $0.89(0.32)$, and refractive index of 3.62 (1.0). The saponification, acid, iodine and peroxide values of the oil were 45.81 (5.19), 9.16 (0.21), 64.80 (4.31) and 10.50 (1.50) respectively.

Conclusion: The results suggest that the oil has a potential for use as vegetable oil, in industries and, subject to further evaluation of the contents, health promoting purposes.

Key words: honeydew melon, oil, physico-chemical characteristics

\section{Introduction}

There has been an emerging interest in the compounds that occur naturally in plants and their extracts owing to their therapeutic and risk minimizing potentials for many chronic diseases such as cardiovascular diseases, cancers, diabetes and neurodegenerative diseases like Alzheimers' disease $(1,2)$. Honeydew melon (Cucumis melo) (Figure 1A) also called sweet melon or golden melon is grown in temperate climatic regions of the world including Nigeria (in West Africa) in which Sokoto state is located. Its wide spread cultivation is as a result of the taste of the fruit and applications in traditional medicine (3). It has been used for cardiovascular diseases, liver and kidney diseases, anaemia, rheumatism and gout (4). The seeds of honeydew melon (Figure 1B) in some parts of the world are regarded as waste, not until some researchers began to explore their benefits such as the use as antioxidants, anti-inflammatory and analgesics (5).

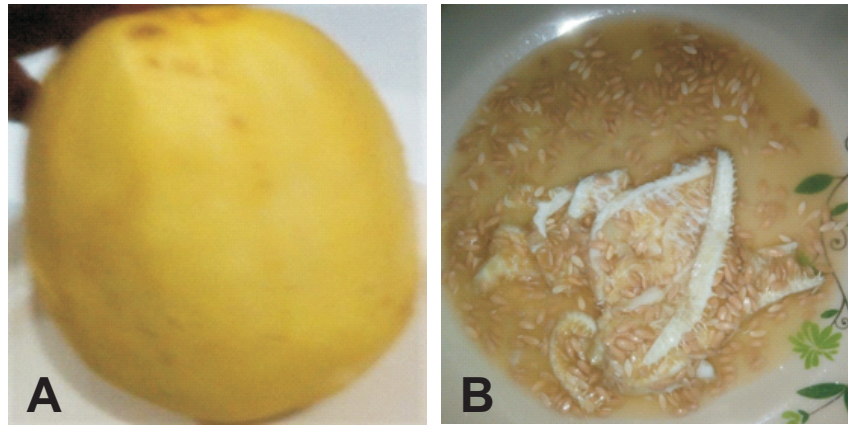

Figure 1. Cucumis melo $L$ (Honeydew melon) $A=$ Fruit, $B=$ Seeds

Hitherto, there appeared to be few reports on the extraction of oil from the seeds and characterisation of the oil especially of the African variety. The reports in other parts of the world showed that the honeydew seed oil is rich in tocopherols, sterols, and phospholipids (6). However, the variation of compositions of the oil depending on the type of the melon and on the area it originates was noted by some researchers $(6,7,8)$. In 
Africa, there is increasing demand for vegetable oils commensurate with the rapid population growth which, in a way, overwhelm the few sources available. Hence, there is need to explore cheaper, safer and nutritionally rich vegetable oils. In the present study, oil was extracted from locally grown honeydew melon seeds and some physical and chemical properties were determined.

\section{Materials and Methods}

\section{Materials}

The honeydew melon fruit was purchased from Gawon nama local market Sokoto. The seeds were harvested from the fruits, dried for 72 hours at $25^{\circ} \mathrm{C}$ and then ground to powder using clean mortar and pestle. The chemical used were of analytical grade. Glass Soxhlet extractor was used for the oil extraction.

\section{Extraction of oil}

Oil was extracted from honeydew melon seed by Soxhlet using n-hexane as the solvent according to AOAC method (9). Fifty grams ( $50 \mathrm{~g})$ of shelled ground seeds were packed into a weighed thimble, which was introduced into the Soxhlet system. About $250 \mathrm{~mL}$ of the solvent (n-Hexane) was poured into the flask. The set up was damped and heated on a heating mantle. The extraction processes were carried out in six hours at temperature of $\mathrm{n}$-Hexane $\left(60^{\circ} \mathrm{C}\right)$. Solution obtained from the extraction was regained through a reflux process for 15 minutes after which the content was evaporated by increasing the temperature to $70^{\circ} \mathrm{C}$ for about half an hour to obtain yellowish, liquid at room temperature oil. The $\mathrm{pH}$ of the oil was determined using digital bench top $\mathrm{pH}$ meter $(\mathrm{pH} / \mathrm{mV} / \mathrm{ISE})$ and was then subjected to further analysis.

\section{Determination of physical characteristics honeydew melon seed oil}

\section{Determination of moisture content}

The moisture content of the oil was determined by airoven method, according to Ghatak and Panchal (10) with slight modification. Five grams $(5 \mathrm{~g})$ of oil were weighed in previously dried, weighed and tared dish. The dish was heated for 1 hour at about $105^{\circ} \mathrm{C}$. The dish was then removed, cooled in a desiccator and then weighed. The dish was heated again for another 1 hour, then was allowed to cool down before being weighed. This was repeated until the change in weight between observations was less than $1 \mathrm{mg}$. The moisture content (percentage by weight) was calculated by $\frac{\mathrm{W} 1}{\mathrm{~W}} \times 100$

Where $\mathrm{W} 1$ = weight loss $(\mathrm{g})$ of the sample on heating $\mathrm{W}=$ weight of the sample $(\mathrm{g})$ taken

\section{Determination of specific gravity}

Specific gravity of the oil was determined according to the method adopted by Ghatak and Panchal (2010) using a specific gravity bottle. The bottle was filled with the oil sample, avoiding entrapment of air bubbles from the side arm, stopper was replaced and then immersed in the water bath at $25^{\circ} \mathrm{C}$ and held for 30 minutes. The bottle was then removed from the water bath and dried. The cap of the side arm was removed and the bottle quickly weighed. This was repeated using water instead of the oil.

The specific gravity of the oil was calculated by

Specific gravity at $25^{\circ} \mathrm{C}=\underline{\mathrm{A}-\mathrm{B}}$

Where $\mathrm{A}=$ weight in gram of specific gravity bottle with oil at $25^{\circ} \mathrm{C}$

$\mathrm{B}=$ weight in gram of specific gravity bottle at $25^{\circ} \mathrm{C}$

$\mathrm{C}=$ weight in gram of specific gravity bottle with water at $25^{\circ} \mathrm{C}$

\section{Determination of refractive index}

The refractive index of the oil was determined using Abbe refractometer at $25^{\circ} \mathrm{C}$ (AOAC 921.08). Few drops of the oil were placed, ensuring complete cover and avoiding bubbles, on the polished surface of the measuring prism. The illuminating prism was brought into contact with the measuring prism and reading was taken. The procedure was repeated thrice and average and standard deviation of the readings were taken.

\section{Determination of chemical charateristics of honeydew melon seed oil}

\section{Determination of saponification value}

Saponification value of the oil was determined according to AOAC method (1976). Four grams (4g) of oil was weighed into a flask. From burette, $50 \mathrm{~mL}$ of alcoholic $\mathrm{KOH}$ was added and it was allowed to drain for a definite period of time. The blank was prepared by taking $50 \mathrm{~mL}$ of alcoholic $\mathrm{KOH}$ which was allowed to drain at the same duration of time. Air condenser was connected to the flasks and they were gently boiled for about 1 hour. When the flask and condenser got cooled, the condenser was 
rinsed using distilled water (just a little of it). It was then removed and $1 \mathrm{~mL}$ of the indicator was added. The mixture was then titrated against $0.5 \mathrm{~N}$ HCL until the pink colouration disappeared.

The saponification value was calculated from the titre value as follows:

Saponification value $=\frac{28.05 \times(\text { titre value of blank-titre value of sample })}{\text { Weight of sample(g) }}$

\section{Determination of Iodine value}

Iodine value of the oil was determined according to the AOAC (1996) method. The oil sample (250 mg) was weighed into an Iodine flask and $10 \mathrm{~mL}$ of chloroform was dissolved. $25 \mathrm{~mL}$ of iodine solution was added using a pipette. It was drained in a definite time, well mixed, and then allowed to stand in a dark cupboard for about 30 mins with occasional shaking. $10 \mathrm{~mL}$ of $15 \% \mathrm{KI}$ was added and shaken thoroughly. Freshly boiled and cooled down water $(100 \mathrm{~mL})$ was added. Free Iodine on the stopper was washed down. The mixture was then titrated against $0.1 \mathrm{~N}$ sodium thiosulphate until the yellow solution turned colourless. A few drops of $1 \%$ starch (as indicator) was added and again, it was titrated until the blue colour disappeared completely. Iodine value was calculated by

$\mathrm{IV}=\frac{12.69 \times \mathrm{N}(\mathrm{V} 2-\mathrm{V} 1)}{\mathrm{W}}$

Where $\mathrm{N}=$ normality of sodium thiosulphate, $\mathrm{V} 2=$ volume $(\mathrm{mL})$ of sodium thiosulphate for blank, $\mathrm{V} 1=$ volume $(\mathrm{mL})$ of sodium thiosulphate consumed by sample and $\mathrm{W}=$ weight $(\mathrm{g})$ of sample, 12.69 is a constant based on grams of iodine in $0.1 \mathrm{~mol}$ iodine solution.

\section{Determination of peroxide value}

Peroxide value of the oil was determined according to AOAC (1990). One gram (1 g) of the oil was weighed into a clean dry tube and $1 \mathrm{~g}$ of potassium iodide was added to $20 \mathrm{~mL}$ of solvent mixture. The tube was placed into boiled water, the liquid boiled rigorously within 30 seconds. The content was transferred quickly into a conical flask which already contained $20 \mathrm{~mL}$ of $5 \%$ potassium iodide solution. Each time the tube was washed twice with $25 \mathrm{~mL}$ of water and collected into the conical flask. It was then titrated against $0.1 \mathrm{M}$ sodium thiosulphate solution until the yellow colour disappeared. $0.5 \mathrm{~mL}$ of $1 \%$ starch solution was added. It was shaken vigorously and then titrated carefully until the blue colouration disappeared. A blank without the oil was also determined. PV (meq/Kg) was calculated as follows

$$
\mathrm{PV}(\mathrm{meq} / \mathrm{Kg})=\frac{\mathrm{M} \times\left(\mathrm{V}-\mathrm{V}_{0}\right) \times 1000}{\text { Weight of sample }(\mathrm{g})}
$$

Hence $\mathrm{M}$ is the molar concentration of sodium thiosulphate, $\mathrm{V}$ is the volume of titrant for sample and $\mathrm{V}_{0}$ volume of titrant for blank.

\section{Statistical analysis}

Results were analysed using Microsoft excel 2016. Data were presented as mean $(S D)$.

\section{Results and Discussion}

The results for physical characteristics of honeydew melon seed oil are as depicted in table 1 . The colour of the oil was found to be yellowish which often indicates the presence of carotene (11). Colour often indicates an aesthetic quality of oil and guides bleaching and deodorization processes (12). Most oils are sold based on their colour and each type has sell by colour instructions.

Table Physical properties of honeydew melon seed oil at room temperature

\begin{tabular}{ll}
\hline Parameters & Value \\
\hline Colour & Yellow \\
Physical state at room temperature & Liquid \\
$\%$ yield & $27.49(0.19)$ \\
$\%$ moisture & $2.40(0.91)$ \\
$\mathrm{Ph}$ & $6.21(0.01)$ \\
Specific gravity $\left(\mathrm{g} / \mathrm{cm}^{3}\right)$ & $0.88(0.02)$ \\
Refractive index & $3.62(0.9)$ \\
\hline
\end{tabular}

Data presented as mean $(S D)$

The physical status of the oil was liquid at room temperature. This indicates the presence of, predominantly, unsaturated fatty acids which characteristically kink to prevent packing together, thus making the oil liquid. Oils containing high amount of unsaturated fatty acids have been shown to confer protection against the risk of cardio-vascular diseases $(13,14)$. The percentage yield of oil $27.49 \%$ was lower than previously reported $44.89 \%$ (8), 41.6\% (15); and was higher than what was reported by Yanty et al. (16). The variation could largely be due to the variety of the melons used, solvent used, extraction time, and to some extent the methods of oil extraction. For Yanty et al. (16) used petroleum ether, while n-Hexane was used in this study and this could explain the reason for the variation. The variation in oil yield of this study and that of Petkova and Antova (15) is likely due to extraction times (6 vs 8 
hours respectively). However, variety of the melons could account for the yield variation of this study (Cucumis melo L) with that of Ibeto et al. (Cucumis melo Cylindrica) (8).

Lower moisture content has been reported to increase oil recovery and decrease oil loss during cooking (17). The refractive index of oils tells about their purity, molecular weight, fatty acid chain length, degree of un-saturation, and degree of conjugation (18). Honeydew melon seed oil has a refractive index higher than that of water whose refractive index is 1.334 . The refractive index of an oil is dependent on its density and reflects fatty acid chain length, degree of unsaturation and triglycerides contents of the oil (8). Values of refractive index increases with increase in the levels of triglycerides, because triglycerides have higher refractive indices than free fatty acids (19). Yanti and colleagues (16) reported high triglycerides in melon seed oil with predominant linoleic acid. Hence, the high refractive index obtained in this study could be due to high triglycerides content of the oil, however, triglycerides were not determined. It is important to note that, triglycerides serve as primary energy stores in the body and provide fatty acids for phospholipids biosynthesis which are important constituents of cell membrane. However, excessive triglyceride has been reported as an independent risk to development of cardiovascular disease (22).

The results of the chemical characteristics of melon seed oil are as depicted in table 2. Saponification value, a measure of tendency to soap formation and difficult separation of oils, indicates the presence of high amount of fatty acids (20). The saponification value of the oil in this study is lower than most reported previously, thus the oil may not be suitable for soap making, however, could be utilized for biodiesel formation, since low saponification value allows for separation (8).

Table 2 Chemical characteristics of honeydew melon seed oil at room temperature

\begin{tabular}{ll}
\hline Parameters & Value \\
\hline Saponification value $(\mathrm{mg} \mathrm{KOH} / \mathrm{g})$ & $45.81(5.19)$ \\
Acid value $(\mathrm{mg} \mathrm{KOH} / \mathrm{g})$ & $9.16(0.21)$ \\
Iodine value $(\mathrm{gI} / \mathrm{I} / \mathrm{OOg})$ & $64.80(4.31)$ \\
Peroxide value $(\mathrm{meq} / \mathrm{Kg})$ & $10.50(1.50)$ \\
\hline
\end{tabular}

Data presented as mean $(S D)$

Acid value an important measure of rancidity of oils, usually formed from hydrolysis of triglycerides was $9.6(0.21) \mathrm{mgKOH} / \mathrm{g}$. This value is above the permissible level of less than 1, thus the oil has high potential of rancidity within short time. However, the high acid value could be as a result of high triglycerides suggested by high refractive index.

The Iodine value obtained for honeydew melon seed oil, which measures the degree of unsaturation was lower than the ranges for different oils reported by previous studies $(8,10,15,16,21)$. However, it is within FAO/WHO acceptable limits of $50-129 \mathrm{gI}_{2} / 100 \mathrm{~g}$. iodine value influences long-term stability properties of oil which is important for storage. The peroxide value, a measure of oxidation products of oils was slightly higher than previously reported (8). However, this may not be unconnected to the presumably high levels of triglycerides.

\section{Conclusion}

This study revealed that honeydew melon seed is a promising source of healthy vegetable oil that is fairly stable oxidatively and has potential for use in industries and production of biodiesels. The health potential of this oil is high if further explored for the presumptive triglyceride contents. The Iodine value being within acceptable limit also confers potential long-term stability to the oil, a good factor for storage. However, the oil may be highly rancid due to the high acid value. Studies are underway for fatty acids profile and bioactive components; and possible testing of the bioactive components of the oil.

\section{Acknowledgements}

The authors acknowledge the Department of Biochemistry, Usmanu Danfodiyo University, Sokoto for facility support.

\section{Reference}

1. Frank N, Andrews FM, Elliott SB, Lew J, Boston RC. Effects of rice bran oil on plasma lipid concentrations, lipoprotein composition, and glucose dynamics in mares. J. Anim. Sci. 2005;83(11):2509-18.

2. Stevinson $C$, Pittler MH, Ernst E. Garlic for treating hypercholesterolemiaA meta-analysis of randomized clinical trials. Ann. Intern. Med. 2000;133(6):420-9.

3. Bates DM, Robinson RW, Jeffrey C. Appendix: An Outline Classification of the Cucurbitaceae. In: Biology and Utilization of the Cucurbitaceae. 2019.

4. Ivanova PH. The melons-raw material for food processing. In: 50 years FoodRDI Food Technologies and Health, International Scientific-Practical Conference, Plovdiv, Bulgaria, 8 November 2012 Proceedings. Food Research and Development Institute; 2012. p. 23-6.

5. Chen L, Kang YH, Suh JK. Roasting processed oriental melon (Cucumis melo L. var. makuwa Makino) seed influenced the triglyceride profile and the inhibitory potential against key enzymes 
Physico-chemical Characteristics of Sokoto Locally grown Cucumis melo L (Honeydew Melon) Seed Oil

relevant for hyperglycemia. Food Res Int. 2014;

6. Azhari S, Xu YS, Jiang QX, Xia WS. Physicochemical properties and chemical composition of Seinat (Cucumis melo var. tibish) seed oil and its antioxidant activity. Grasas y Aceites. 2014;

7. Albishri HM, Almaghrabi OA, Moussa TA. Characterization and chemical composition of fatty acids content of watermelon and muskmelon cultivars in Saudi Arabia using gas chromatography/mass spectroscopy. Pharmacogn. Mag. 2013;

8. Ibeto CN, Okoye COB, Ofoefule AU. Comparative Study of the Physicochemical Characterization of Some Oils as Potential Feedstock for Biodiesel Production. ISRN Renew Energy. 2012;

9. AOAC. "AOAC: Official Methods of Analysis" 18th ed. Assoc Off Anal Chem. 2005;

10. Ghatak SB, Panchal SJ. Methodical characterization and quantitative estimation of crude Oryza sativa bran oil. Int J Chem Anal Sci. 2010;1:181-5.

11. Moyano MJ, Heredia FJ, Meléndez-Martinez AJ. The color of olive oils: The pigments and their likely health benefits and visual and instrumental methods of analysis. Compr Rev. Food Sci. Food Saf. 2010;

12. Umbreit E, Russell M. Do oil color scales make you see red? or yellow? Int News Fats, Oils Relat Mater. 2013;

13. Dietary Guidelines Advisory Committee Reports. Nutr. Today. 2015;

14. Nicolosi RJ. Dietary fat saturation effects on low-density-lipoprotein concentrations and metabolism in various animal models. Am. J.
Clin. Nutr. 1997;65(5):1617S-1627S.

15. Petkova Z, Antova G. Proximate composition of seeds and seed oils from melon (Cucumis melo L.) cultivated in Bulgaria . Cogent. Food Agric. 2015;

16. Yanty NAM, Lai OM, Osman A, Long $K$, Ghazali HM. Physicochemical properties of cucumis melo var. inodorus (honeydew melon) seed and seed oil. J. Food Lipids. 2008;

17. Singh KK, Wiesenborn DP, Tostenson K, Kangas $N$. Influence of moisture content and cooking on screw pressing of crambe seed. J. Am. Oil Chem Soc. 2002;79(2):165-70.

18. Nichols DS, Sanderson $K$. The nomenclature, structure, and properties offood lipids. Chem Funct. Prop. food lipids. 2003;29-59.

19. Shahidi F. Quality Assurance of Fats and Oils. In: Bailey's Industrial Oil and Fat Products. 2005.

20. O. O. Omolara and O. O. Dosumu. Preliminary Studies on the effect of processing methods on the quality of three commonly consumed marine fishes in Nigeria. Biokemistri. 2009;

21. Mishra R, Sharma HK. Effect of packaging materials on the storage stability of physically refined rice bran oil and its blends. African J. Food Sci. 2011;5(12):676-85.

22. Thorin, E.. Vascular disease risk in patients with hypertriglyceridemia: endothelial progenitor cells, oxidative stress, accelerated senescence, and impaired vascular repair. Can. J. Cardiol. 27, 538-540. 2011. 